\title{
Women graduates
}

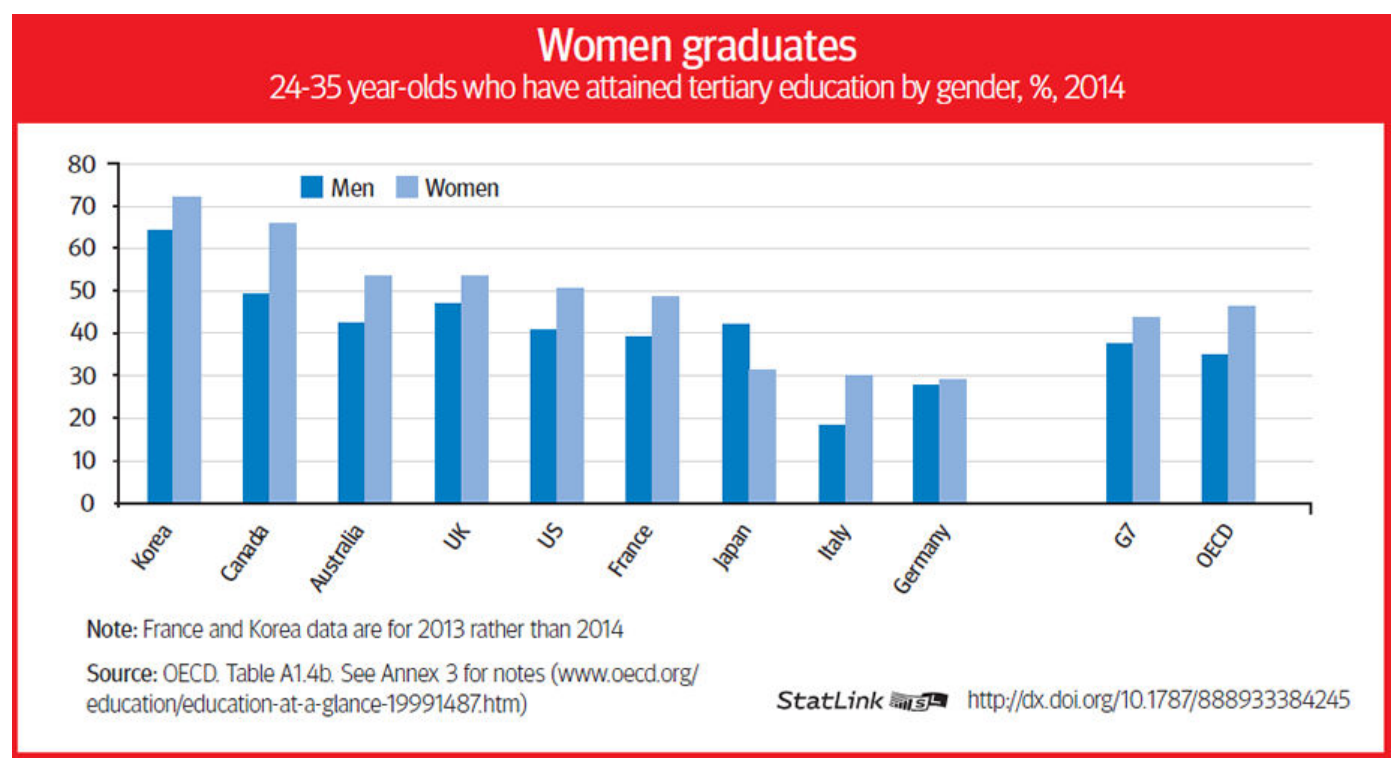

Traditionally, men have tended to be more educated than women in Korea, especially when it comes to higher education. Only 34\% of doctoral graduates or equivalent graduates are women which is among the lowest shares across G7 and OECD countries. However, women in Korea have made great strides in educational attainment over the past decade.

In the OECD PISA tests, for instance, 15 year-old girls now outperform boys in reading assessments. Among younger adults aged 25-34 years old, some $72 \%$ of women have obtained a tertiary education degree, compared with $64 \%$ of men. The gender gap between male and female doctoral graduates has also decreased due to national policies aimed at supporting female human resource development and social activities. Women accounted for $32 \%$ of doctoral graduates in $2011,34 \%$ in 2013 , and $36 \%$ in 2015 . In addition, $63 \%$ of young Korean women reported achieving a higher educational attainment than their parents, which suggests upward generational mobility in education.

Despite these impressive educational achievements, female labour market outcomes remain poor compared with men, with the Korean gender pay gap remaining the highest among OECD countries at $36.6 \%$. Closing it will be a key policy challenge in the years ahead. 
See "Korea's work-life balance policies for sustainable growth" in OECD Yearbook 2015, http://oe.cd/1wk

Visit www.oecd.org/gender and www.oecd.org/pisa 